\title{
MANIFESTAÇÕES OCULARES DE DOENÇAS SISTÊMICAS
}

\author{
OCULAR MANIFESTATIONS OF SYSTEMIC DISEASES
}

Nivaldo Vieira de Souza \& Maria de Lourdes Veronese Rodrigues

Docentes do Departamento de Oftalmologia e Otorrinolaringologia da Faculdade de Medicina de Ribeirão Preto da Universidade de São Paulo.

CORRESPONDÊNCIA: Departamento de Oftalmologia e Otorrinolaringologia da Faculdade de Medicina de Ribeirão Preto - Campus Universitário - CEP: 14048-900 - Ribeirão Preto - SP. Fax: (016) 633-0186.

SOUZA NV de \& RODRIGUES M de LV. Manifestações oculares de doenças sistêmicas. Medicina, Ribeirão Preto, 30: 79-83, jan./mar. 1997.

RESUMO: Os objetivos deste capítulo são: capacitar o estudante de Medicina a nomear as implicações oculares das principais doenças sistêmicas que envolvem o olho, e fornecer subsídios para a educação continuada de médicos de outras especialidades.

UNITERMOS: Manifestações Oculares. Diabetes Mellitus. Hipertensão. Síndrome de Imunodeficiência Adquirida.

Peter Meyer Latham, médico inglês, dizia há quase dois séculos atrás, que, no olho, poderiam ser vistas todas as doenças, em miniatura, e, assim, aprender muito sobre os detalhes dos processos mórbidos, graças às suas características, que permitem o exame como se através de uma janela .

Logicamente, desde então, muito se descobriu não só sobre as doenças, mas, também, sobre os métodos de exame, e os conhecimentos sobre as estruturas oculares tiveram um enorme desenvolvimento, o que fez com que esta especialidade, antigamente um apêndice da cadeira de Cirurgia, se transformasse num microcosmo para estudo de doenças sistêmicas.

\section{MANIFESTAÇÕES OCULARES DO DIABETES MELLITUS}

O comprometimento ocular no Diabetes Mellitus é amplo e grave, com praticamente todas as estruturas, em maior ou menor extensão e severidade, sendo atingidas. Assim temos:

Pálpebras: xantelasma (apesar de pouco específica).
Conjuntiva: alterações na microcirculação (vasodilatação, fluxo sangüíneo lento, etc.)

Músculos extra-oculares: paralisia do III e/ou VI pares.

Córnea: dobras na membrana de Descemet.

Íris: ectrópio da úvea, rubeose e vacuolização.

Cristalino: catarata flutuações na refração.

Corpo ciliar: espessamento da membrana basal.

Humor vítreo: corpúsculos asteróides.

Nervo óptico: atrofia (rara).

Retina: retinopatia e lipemia.

\section{Retinopatia Diabética:}

O Diabetes Mellitus compromete, primariamente, os pequenos vasos da retina, provocando espessamento da membrana basal e desaparecimento dos pericitos intramurais dos capilares retinianos. Como consequiência direta desta microangiopatia diabética, vamos ter uma maior fragilidade capilar com extravasamento de líquido e conseqüente edema e menor aporte sangüíneo, nas regiões irrigadas por estes vasos. Com 
isto, o tecido passa a sofrer hipóxia, com formação e liberação de fator neovasogênico, ainda não perfeitamente determinado, o qual irá provocar a formação de vasos anormais na intimidade e superfície da retina, podendo crescer em direção ao humor vítreo. Depreende-se daí que existem duas fases distintas na retinopatia diabética:

FASE NÃO-PROLIFERATIVA: edema, hemorragias, microaneurismas e exsudatos na retina.

FASE PROLIFERATIVA: evoluindo da fase anterior para uma etapa onde encontramos neoformações vasculares.

Na evolução do processo, estes vasos anormais irão ser tracionados pelo humor vítreo e sangrar, o que poderá ocorrer também por aumento da pressão hidrostática intravascular, uma vez que estes vasos têm paredes muito frágeis. Na resolução destas hemorragias, há formação de fibrose no vítreo, com mais trações, mais hemorragias, mais hipóxia com mais neovasos, terminando o processo com isquemia da retina.

As trações vítreas podem se fazer de tal forma a puxar a retina, levando ao descolamento da mesma.

A exsudação, por outro lado, pode ser tão intensa que a retina toma aspecto amarelado (lipemia retiniana).

O resultado final destes quadros é uma visão muito pobre (vultos) ou totalmente perdida.

A retinopatia diabética é, hoje, uma das principais causas de cegueira, pois, com a evolução terapêutica, a sobrevida destes pacientes aumentou; com a incidência da retinopatia, aumenta, com o passar dos anos; de doença (presente em cerca de $50 \%$ dos diabéticos com 15 anos e em cerca de $80 \%$ daqueles com 25 anos) irá sempre evoluindo, terminando por levá-lo à cegueira (cerca de 5\% dos pacientes com história de 30 anos de doença).

\section{MANIFESTAÇÕES OCULARES DA HIPERTENSÃO ARTERIAL}

O comprometimento ocular, nesta patologia, é de grande importância para o clínico, uma vez que a possibilidade de observação dos vasos sangüíneos retinianos nos permitirá inferir as condições vasculares deste paciente e fazer o estadiamento da doença.

Num fundo de olho hipertensivo, encontram-se exsudatos, hemorragias, estreitamento arteriolar, tortuosidade, ingurgitamento venoso, cruzamentos arteriovenosos patológicos, artérias em "fio de cobre" e "fio de prata" e papiledema.

Dois fatos são importantes de serem lembrados. Existem inúmeras classificações para estadiamento da retinopatia hipertensiva, cada uma delas com suas vantagens e desvantagens; porém, fica difícil o enquadramento de um paciente em um único estágio, pois, nem sempre, as alterações fundoscópicas são bem definidas. Ao lado disso, as alterações hipertensivas se confundem com as ateroscleróticas a partir de certo ponto. Tudo isso faz com que não se tenha uma classificação universalmente aceita. Em vista disso, convém ater-se aos aspectos que tenham, para o clínico, interesse particular, isto é, se a hipertensão é crônica (benigna) ou aguda (maligna).

Assim, é fundamental saber se as alterações no fundo de olho se instalaram agudamente ou se tivemos um pico de agudização sobre uma hipertensão arterial crônica, sendo que, nestes casos, encontram-se alterações do tipo edema, hemorragias e papiledema. Ao lado disso, nos hipertensos crônicos, existem alterações que levaram algum tempo para evoluir até o quadro atual, por exemplo, estreitamento arteriolar, cruzamentos patológicos, ingurgitamento venoso, artérias em "fio de prata", em "fio de cobre" e exsudatos duros.

\section{MANIFESTAÇÕES OCULARES DA AIDS}

Problemas relacionados com a AIDS podem se manifestar em diferentes estruturas do globo ocular e de seus anexos. Apesar de o vírus da imunodeficiência humana (HIV) poder ser isolado de todos os fluidos e tecidos oculares, as principais manifestações ocorrem por infecções oportunistas ou pela reagudização de um processo preexistente.

Aproximadamente metade dos pacientes com AIDS apresentam uma microangiopatia, com nódulos algodonosos (que indicam infarto isquêmico das fibras nervosas superficiais da retina), semelhante ao que ocorre em determinadas fases das retinopatias hipertensiva e diabética. Estes pacientes não apresentam diminuição da acuidade visual e os exsudatos algodonosos constituem achado ocasional.

Na pálpebra, a manifestação mais importante é o Sarcoma de Kaposi, tumor vascular de coloração violácea ou avermelhada, que se apresenta como mácula, nódulo ou pápula e é mais freqüente quando a transmissão da AIDS se faz por relações homossexuais. Normalmente, existem tumores em outras regiões do corpo humano, sendo o tumor palpebral um outro foco e não uma metástase.

As pálpebras podem apresentar, também, lesões provocadas por vírus (principalmente varicela-zoster), por fungos e por bactérias.

O Sarcoma de Kaposi também pode aparecer na conjuntiva, e os pacientes com AIDS estão mais 
sujeitos a conjuntivites e a ceratites (principalmente virais, fúngicas e bacterianas) do que os indivíduos imunocompetentes.

Uveítes, retinites e coriorretinites são bastante frequientes nos pacientes com AIDS, uma vez que o HIV propicia a quebra da barreira sangue/aquoso.

As uveítes são ocasionadas mais freqüentemente por toxoplasmose, sífilis, herpes e tuberculose.

Entre as manifestações oculares com comprometimento visual, a retinite por citomegalovírus é a mais freqüente na AIDS, sendo, algumas vezes, a primeira indicação da doença. Sua alta prevalência faz com que, em alguns países, se faça a profilaxia medicamentosa em pacientes com fatores de risco para citomegaloviroses. Consegue-se preservar a visão e evitar o envolvimento do outro olho, com tratamento precoce e adequado, o qual deve ser mantido pelo resto da vida, pois as recidivas são muito freqüentes. Mais dramáticas são as retinites causadas por vírus do complexo varicela-zoster: necrose retiniana externa progressiva (PORN) e necrose retiniana aguda (ARN).

As coriorretinites são mais comumente causadas pelo Pneumocystis carinii e pelo Criptococus neoformans, devido à alta frequiência das infecções sistêmicas por estes agentes.

\section{MANIFESTAÇÕES OCULARES DE OUTRAS DOENÇAS SISTÊMICAS}

\section{DOENÇAS METABÓLICAS HEREDITÁRIAS}

São conhecidas mais de uma centena de doenças metabólicas hereditárias (DMH) sendo que metade delas, geralmente ou sempre, comprometem o globo ocular ou seus anexos.

Não serão mencionadas todas, mas, somente as mais freqüientes, associando-as à estrutura ocular afetada.

Pálpebra: xantelasma - hiperlipoproteinemia; blefaroptose: abetalipoproteinemia.

Músculos oculomotores: estrabismo - D.Gaucher.

Esclera: cor azulada - osteogênese imperfeita.

Conjuntiva: alterações vasculares - hemoglobinopatias; icterícia: anemias hemolíticas e hiperbilirrubinemia.

Íris: despigmentação - albinismo e fenilcetonúria.

Córnea: pigmentação - alacaptonúria (também na esclera).

D.Wilson (anel Kaiser-Fleischer); distrofia - amiloidose hereditária; turvação: mucopolisacaridoses e mucolipidoses.
Cristalino: catarata - galactosemia. S.Lowe, distrofia miotônica, D.Wilson.

Subluxação: S.Ehlers - Danlos, S.Marfan; catarata + subluxação - homocostinúria, W.Weill - Marchesani.

Retina: descolamento de retina - S.Ehlers - Danlos, homocistinúria, S.Marfan; degeneração macular - gangliosídeos, D.Niemann Pick; despigmentação - albinismo; retinopatia pigmentosa - abetalipoproteinemia, MPS (Hunter), S. Marfan; alterações vasculares - hiperlipoproteinemia, hemoglobinopatia, D.Febry; atrofia óptica.

Corpo vítreo: turvação - amiloidoses.

\section{DOENÇAS REUMÁTICAS E DO COLÁGENO}

Todas estas doenças, freqüentemente, comprometem o olho:

Artrite reumatóide: esclerite e ceratoconjuntivite seca. Artrite reumatóide juvenil (S.Still): iridociclite.

Espondilite anquilosante: iridociclite.

Espondilite anquilosante: iridociclite e uveíte.

S. Reiter: uretrite, conjuntivite, artrite e diarréia (colite).

Lupus eritematoso sistêmico: retinopatia (exsudatos algodonosos).

Arterite de células gigantes: neurite óptica e isquêmica - que levam à atrofia óptica e cegueira.

\section{DOENÇAS NUTRICIONAIS}

A má nutrição é uma das principais causas de cegueira nos países em desenvolvimento.

A deficiência específica de vitaminas do complexo B, apesar dos achados discordantes na literatura, leva à vascularização e a distrofias no epitélio da córnea e ao quadro, chamado "ambliopia nutricional", condição endêmica em certos pontos do mundo.

A hipovitaminose A manifesta-se no olho, especialmente de crianças em idade pré-escolar, através de alterações:

\section{Segmento anterior:}

X1A - Xerose conjuntival: secura da conjuntiva com perda do brilho e enrugamento da mesma;

X1B - manchas de Bitot: formação elevada que aparecem na conjuntiva bulbar interpalpebral;

X2 - xerose da córnea: semelhante à da conjuntiva;

X3 - úlcera de córnea/ ceratomalácia (necrose coliquativa da córnea, deixando lesão irreversível e cegueira, quando não leva à perfuração do globo ocular).

XS - cicatrizes na córnea. 


\section{Segmento posterior do olho:}

XN - cegueira noturna (hemeralopia): condição caracterizada por demora ou impossibilidade na adaptação visual em ambientes escuros;

XF - fundo de olho "xeroftálmico".

\section{DOENÇAS HEMATOLÓGICAS}

De modo geral, as leucemias, síndrome de hiperviscosidade (macroglobulinemia, mieloma múltiplo, ocasionalmente D.Hodgkin e outros linfomas), policitemias, anemias, etc. levam a hemorragias na retina e coróide, decorrentes de dilatação venosa com tortuosidade, presença de cruzamentos patológicos, oclusão venosa, que terminam nas hemorragias, exsudatos e atrofia da retina.

\section{DOENÇAS DERMATOLÓGICAS}

A principal doença que envolve a pele e tem manifestações oculares importantes é a hanseníase. O Mycobacterium leprae acomete o olho pela invasão direta do segmento anterior ou indiretamente, através das deficiências neurológicas e, ou das lesões cutâneas. As principais manifestações são: iridociclites, opacificações corneanas (resultantes da lagoftalmia e da diminuição da sensibilidade da córnea), perda de sobrancelhas e de cílios, alterações da pressão ocular, dacriocistites, episclerites e esclerites, conjuntivites e cataratas.

A associação de doenças da pele e alterações oculares é conhecida há muito tempo. Não vamos citar as outras doenças dermatológicas, pois, praticamente, todas podem se manifestar no olho.

Só vamos lembrar que tanto o dermatologista pode dar importante contribuição no diagnóstico de achados oculares, como o oftalmologista, com base nos achados em exame ocular, pode auxiliar o dermatologista, tanto na identificação da patologia, como, principalmente, na terapêutica, em casos de envolvimento ocular.

\section{DOENÇAS GASTROINTESTINAIS}

Existem diferentes modos de identificar como significante a associação entre doença ocular e em outros órgãos. Por exemplo, utilizando a semelhança histológica, identificação de microorganismos idênticos em ambos os processos, reações semelhantes "in vitro"e "in vivo", etc.

No caso das doenças gastrointestinais e oculares, o argumento de "resposta terapêutica" tem mostrado que esta associação deve ser valorizada; apesar de ainda não se ter maiores comprovações da melhora dos processos inflamatórios oculares (conjuntivite, ceratoconjuntivite, iridociclite, neurite, etc.), após tratamento de processos gastrointestinais, como: enterocolite granulomatosa de Crohn, doença de Whipple (epodistrofia intestinal), parasitas intestinais (ameba, giardia, endolimax, estrongilóide, etc.) e úlcera péptica.

\section{OUTRAS DOENÇAS ENDÓCRINAS}

Apesar de o Diabetes Mellitus ocupar lugar de destaque na associação das doenças endócrinas e alterações oculares, existem outras que devem ser lembradas:

Tireóide - D.Graves: edema palpebral, proptose, oftalmoplegia, ceratite, lesão do nervo óptico, etc.;

- hipotireoidismo: edema, ptose, ceratopatia seca, etc.

Hipófise - hiperparatireoidismo: depósitos de cálcio na conjuntiva e córnea;

hipoparatireoidismo: ceratoconjuntivite, catarata e papiledema.

Supra-Renal - hipertensão arterial.

NV de \& RODRIGUES Mde LV. Ocular manifestations of systemic diseases. Medicina, Ribeirão Preto, 30: 79-83, jan./march 1997.

ABSTRACT: The main objectives of this section are to enable the medical student to describe the ocular manifestations of some systemic diseases and to provide material for continuing medical education.

UNITERMS: Eye Manifestations. Diabetes Mellitus. Hypertension. Acquired Immunodeficiency Syndrome. 


\section{REFERÊNCIAS CONSULTADAS}

1 - FOSS NT. Problemas da pele e mucosas. In: RODRIGUES MLV, org. Oftalmologia clínica. Cultura Médica, Rio de Janeiro, p. $458-469,1992$

2 - FIGUEIREDO JFC. Inter-relações de condições clínicas sistêmicas e complicações oculares na AIDS. In: Anais, XXX Reunião Anual do Centro de Estudos Oftalmológicos "Cyro de Rezende". Ribergráfica, Ribeirão Preto, p. 21-22, 1995.

3 - RODRIGUES MLV. Deficiências de dietéticas. In: KARA-JOSÉ N \& BELFORT Junior R. Córnea - Clínica e cirúrgia. Roca, São Paulo, p. 619-626, 1996.
4 - ORELLANA J; LIEBERMAN RM \& TEICH SA. Ocular manifestations of AIDS. Igako-Shoin, New York, 105p, 1995.

5 - RODRIGUES MLV. Prevenção de perdas visuais. In: RODRIGUES MLV, org. Oftalmologia clínica. Cultura Médica, Rio de Janeiro, p. 502-522, 1992.

6 - RODRIGUES MLV; SOUZA NV \& FIGUEIREDO JFC. AIDS: ocular manifestações in Brazil. Ocular AIDS Satellite Meeting. In: XI International Conference on AIDS. Vancouver, Canadá. 1996. Typescript.

7 - SOUZA NV. O olho e outros sistemas. In: RODRIGUES MLV, org. Oftalmologia para alunos de graduação em medicina. Legis Summa, Ribeirão Preto, Cap. 70, p. 77-84, 1992. 